\title{
Relationship between body and testis temperatures in the European hedgehog, Erinaceus europaeus, during hibernation and sexual reactivation
}

\author{
P. A. Fowler* and P. A. Racey \\ Department of Zoology, University of Aberdeen, Aberdeen AB9 2TN, U.K.
}

\begin{abstract}
Summary. Simultaneous telemetry of the body and testis temperatures of 8 hedgehogs was carried out during hibernation and during sexual reactivation in spring. Between October and January, when the testes were involuted, the body/testis temperature differential was variable, with mean daily testis temperatures up to $1^{\circ} \mathrm{C}$ warmer than body temperatures. From mid-February onwards, when plasma testosterone approached maximal concentrations, mean testicular temperatures stabilized $1.4 \pm 0 \cdot 2^{\circ} \mathrm{C}$ below body temperatures. During spermatogenesis testicular temperature of hedgehogs was significantly lower than body temperature. Over the euthermic body temperature range of $34.7-36.2^{\circ} \mathrm{C}$, testicular temperatures varied from 34.0 to $34.9^{\circ} \mathrm{C}$. Only at body temperatures over $36.2^{\circ} \mathrm{C}$ did testicular temperature reach $35^{\circ} \mathrm{C}$. During spermatogenesis hedgehog testis temperatures are similar to those of many scrotal mammals.
\end{abstract}

\section{Introduction}

It has been suggested (Moore, 1923, 1926) that the selection pressure resulting in the evolution of the scrotum was the reduction of testicular temperatures, with a corresponding reduction in the spontaneous mutation rate inherent in spermatogenesis (Ehrenberg et al., 1957). In scrotal mammals testicular temperature usually ranges between 2 and $7^{\circ} \mathrm{C}$ cooler than body temperature (Wislocki, 1933; Phillips \& McKenzie, 1934; Waites, 1970, 1976). This differential is maintained by a combination of arterial cooling, and scrotal heat loss. More recently, Bedford (1977) suggested that the epididymis was the prime mover in the evolution of the scrotum, lower testicular temperature being required for sperm maturation and storage in scrotal species.

In testicond mammals, including elephants and hyraxes, testicular temperature may equal body temperature at $38^{\circ} \mathrm{C}$ (Millar \& Glover, 1973; Hanks, 1977), while in the shrew Suncus murinus body temperature is $1.3^{\circ} \mathrm{C}$ higher than testicular temperature (Hasler \& Nalbandov, 1974). In most eutherians testicular temperature is maintined below that of the body by the countercurrent heatexchange mechanism of the spermatic cord and pampiniform plexus (Setchell, 1978), which cools the arterial blood supply to the testis. The European hedgehog, Erinaceus europaeus, is an ascrotal insectivore with the testes located within the abdominal cavity close to the body wall (Type III; Carrick \& Setchell, 1977) and supplied with blood via a pampiniform plexus (Harrison \& Weiner, 1949).

Carrick \& Setchell (1977) cited a body/testis temperature differential for the European hedgehog of $+0 \cdot 7^{\circ} \mathrm{C}$, but used a low estimate of hedgehog body temperature. Lohiya \& Dixit (1975) reported that in the long-eared hedgehog (Hemiechinus auritus) body temperature was about $1.0^{\circ} \mathrm{C}$ higher than testicular temperature.

*Present address: Department of Bio-Medical Physics, University of Aberdeen, Foresterhill, Aberdeen AB9 2ZD, U.K. 
In European hedgehogs Leydig cell indices (number and size of cells in testis) and plasma testosterone concentration increase rapidly from the second half of hibernation and peak about 1 month before the maximal development of seminiferous tubules and spermatogenesis (Dutourne \& Saboureau, 1983). Similarly Leydig cell indices and plasma testosterone values decline 1 month in advance of seminiferous tubule regression in late summer or early autumn (Saboureau, 1981). Circulating testosterone concentrations are therefore an accurate predictive index of reproductive condition in the male hedgehog. During the first half of hibernation spermatogenesis stops at the primary spermatocyte stage (Allanson, 1934; Saure, 1969).

The aim of the present study was to determine the body/testis temperature differential in the European hedgehog, and investigate changes, if any, in this differential over periods of heterothermy, during hibernation and sexual reactivation in spring.

\section{Materials and Methods}

Animals. The hedgehogs were captured in Aberdeenshire, N.E. Scotland, at $57^{\circ} 6^{\prime} \mathrm{N}$ and were housed in outdoor pens containing nest-boxes, at Culterty Field Station. Food, consisting of day-old chicks, cat food and dog meal, and water, were provided ad libitum. The animals were subjected to minimum disturbance, and exposed to natural photoperiod and ambient temperatures.

Temperature telemetry. Temperature-sensitive radio transmitters (AVM Instruments, Ltd, Dublin, U.S.A.) were used to determine both body and testis temperatures. In the latter case the thermistors were mounted on the end of probes $30-60 \mathrm{~mm}$ long. The transmitters were tuned within the $173-174 \mathrm{MHz}$ wavelength and both body and testis temperature transmitters in situ totalled under $10 \%$ of the hedgehog's body mass.

The transmitters were calibrated to an accuracy of $0 \cdot 1{ }^{\circ} \mathrm{C}$, up and down the temperature scale to check for hysteresis, both before and after implantation, in order to monitor calibration drift. Surgical grade acrylic and a paraffin/ elvax compound (Mini-mitter, Inc., Sunriver, U.S.A.) were used to coat the body temperature transmitters. The testis temperature transmitters were given final coatings of surgical grade elastomer (Dow Corning, Ltd, Reading, U.K.), which allowed full flexibility of the stalked thermistor probes.

Laparotomy was carried out on 8 male hedgehogs anaesthetized with $5 \%$ halothane (ICI plc, Macclesfield, U.K.)/ $\mathrm{O}_{2}$ mixture, using a Boyle's Apparatus (British Oxygen Co. Ltd, Brentford, U.K.). The body temperature transmitters were allowed to move freely within the peritoneal cavity. The thermistor tips of the testis temperature transmitters were stitched into the testis through a $<5 \mathrm{~mm}$ incision made through the tunica albuginea, on the pole opposite in ductuli efferentes. Draw-string sutures held the thermistor head well within the testis itself. The transmitters were implanted at intervals: into 2 males in October, 2 males in December, 2 males in January and 2 males in February, in order to reduce any effect of surgery on the timing of testicular reactivation. Precautionary postoperative treatment involved topical aerosol spray (Terramycin antibiotic. Pfizer Limited, Sandwich, U.K.), and intramuscular administration of a broad-spectrum antibiotic (Streptopen, Glaxovet Ltd, Harefield, U.K.). The hedgehogs were kept overnight in a room at $24^{\circ} \mathrm{C}$ before being returned to their outdoor pens. No results were collected for 2 weeks after surgery in case of short-term inflammation of the testis. All transmitters were removed within 10 months of implantation.

An aluminium dipole antenna was located at one end of the hedgehog quarters at Culterty, and connected to one of two data-collection systems: either a Sharp microcomputer (Sharp Ltd, Manchester, U.K.)/Fliptrack radio receiver (AVM Instruments, Ltd., Dublin, U.S.A.) or a BBC 'B' (Acorn Computers Ltd, Cambridge, U.K.)/Falcon V radio receiver (Wildlife Materials, Inc., Carbondale, U.S.A.) system. Data were collected at 30-min intervals, over consecutive 24-h periods (09:00-08:30 h GMT). All data collected were periodically transferred to a Honeywell Level 66 mainframe computer for processing and analysis.

Blood samples were taken, by cardiac puncture, from all 8 hedgehogs at least once during the periods when they had the temperature transmitters implanted.

Testosterone assay. Plasma testosterone concentrations were determined using heterologous, double-antibody, radioimmunoassay kits (RIA (UK) Ltd, Washington, U.K.) The primary antiserum was raised against testosterone19-carboxymethylether-BSA in rabbits, with a goat anti-rabbit precipitating antibody. No extraction was performed, hedgehog plasma being incubated with iodinated testosterone, primary antiserum and sex binding globulin inhibitor solution (SBGI). Separation was achieved by the addition of the second antibody, incubation and centrifugation. Duplicate samples were counted for $10 \mathrm{~min}$ in an LKB gamma counter. Standards ranged from 10 to $0.1 \mathrm{ng} / \mathrm{ml}$, and specified cross-reactivity was $3 \cdot 4 \%$ with $5 \alpha$-dihydrotestosterone, $2 \cdot 2 \%$ with $5 \alpha$-androstane- $3 \beta, 17 \beta$-diol, $2 \cdot 0 \%$ with 11 -oxotestosterone and minimal with other steroids. Hedgehog plasma dilution (1:5, 1:12.5, 1:25 and 1:50) was closely parallel to the standard curve and the recovery of unlabelled testosterone from pooled hedgehog plasma was both linear and proportional. The minimum testosterone level distinguishable from the assay blank (zero standards treated in the same way as other standards) was $0.05 \mathrm{ng} / \mathrm{ml}$. All hedgehog plasma samples above the maximum standard were diluted 1:5 and re-assayed. The intra- and inter-assay coefficients of variation were 10.8 and $13.4 \%$ respectively. 
Statistical analysis. Differences between body and testis temperatures were tested by analysis of variance (ANOVA) or two-sample $t$ test (Zar, 1984). Fitted least-squares linear regressions were compared by $t$ testing and relationships between variables by simple linear correlation coefficients, $r$ (Snedecor \& Cochran, 1980). When given, values are quoted \pm s.d.

\section{Results}

Over 2200 simultaneous measurements of body and testicular temperatures were made between October 1983 and April 1985, from 8 adult male hedgehogs. There were no apparent side-effects of the surgical techniques, and animals autopsied at the end of the study showed no signs of orchitis or excessive fibrosis in the region of the thermistor. Mean concentrations of plasma testosterone between October and April in thermistor-implanted hedgehogs $(n=2-4 / \mathrm{month})$ were $7.48 \pm 6.48 \mathrm{ng} / \mathrm{ml}$ against $8.71 \pm 6.62 \mathrm{ng} / \mathrm{ml}$ in non-implanted $(n=8 /$ month) male hedgehogs (ANOVA, $P>0 \cdot 05$ ). At no time did testosterone levels in the experimental males fall outside the s.d. range of testosterone titres in control males during the same month.

The mean daily body/testis temperature differential was determined by subtracting testicular temperatures from body temperatures ( 48 values for each 24 -h period) and calculating the mean and standard deviation. Mean daily body/testis temperature differentials were divided into two categories: those measured in euthermic hedgehogs, and those measured in hibernating hedgehogs. Periods of low body temperatures, particularly under $15^{\circ} \mathrm{C}$, indicated the occurrence of hibernation.

No trend in the body/testis temperature differential from hibernating hedgehogs, between October and April, was observed (Fig. 1), testicular temperatures ranging between $2^{\circ} \mathrm{C}$ above or below those of the body. Euthermic hedgehogs had testicular temperatures above body temperatures between October and December. However, from January to March there was a marked $(r=0.827, P<0.001)$ reversal of this trend and testicular temperature was $1 \cdot 2-1 \cdot 6^{\circ} \mathrm{C}$ cooler than body temperature (ANOVA, $P<0.001$ ).

From October to December in euthermic hedgehogs, and throughout winter in hibernating hedgehogs, the circadian relationship between body and testicular temperature was variable, with little distinction between which was the warmest. However, from January to April, body

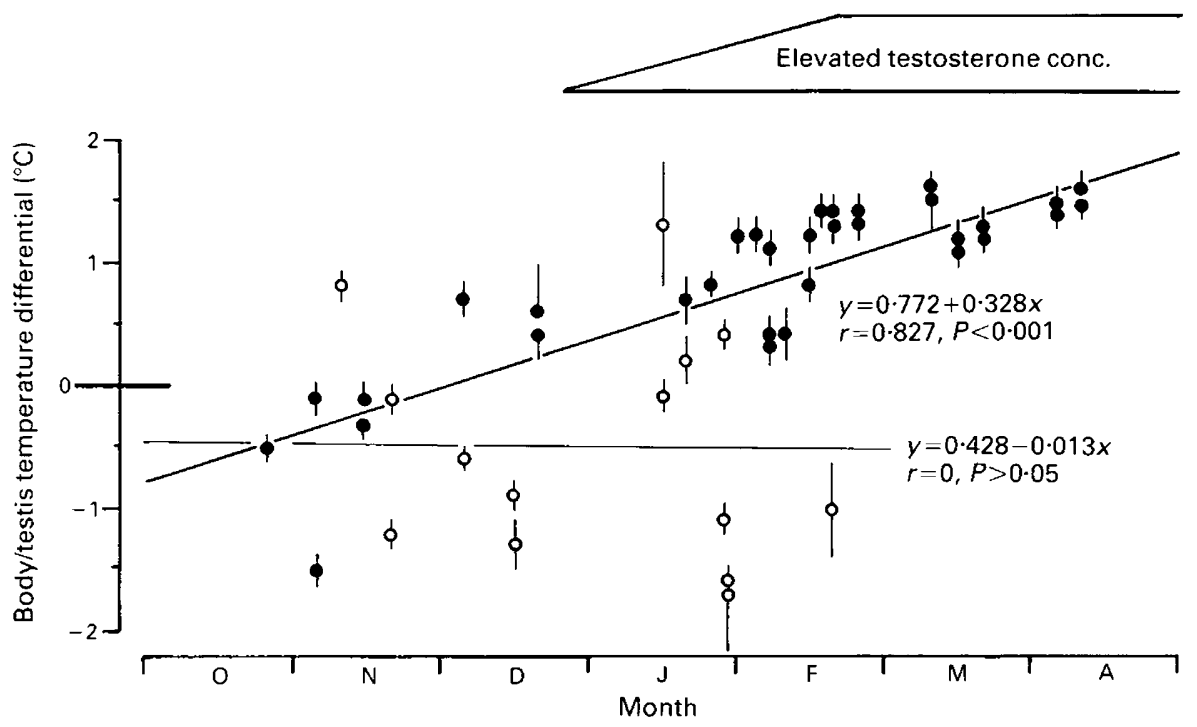

Fig. 1. The mean daily body/testis temperature differential in active (O) and torpid $(O)$ male hedgehogs. Values are mean \pm s.d. 

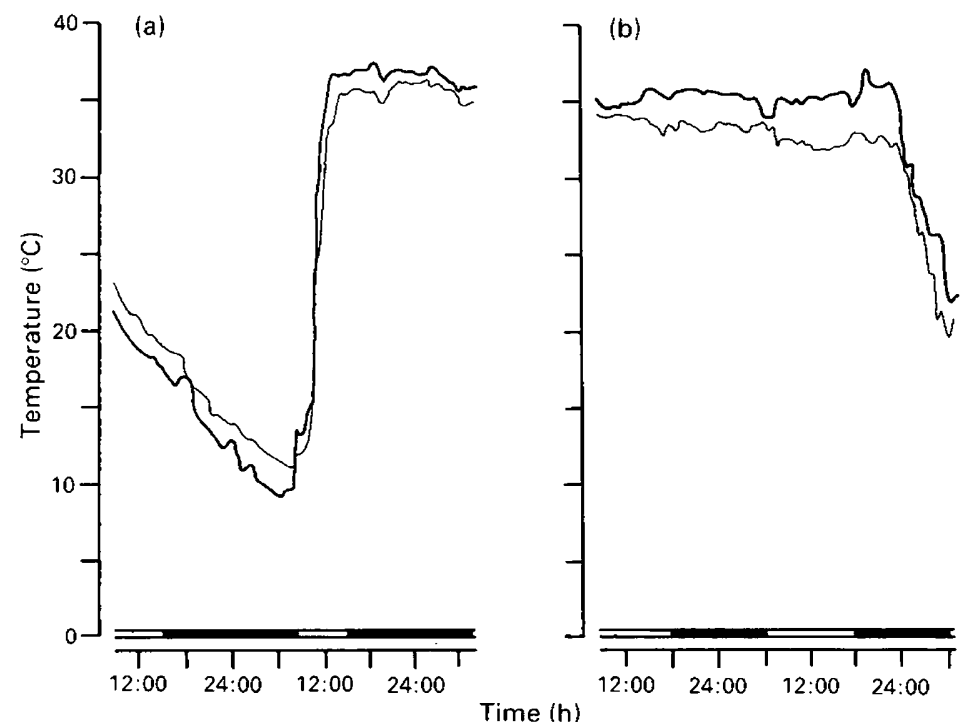

Fig. 2. Examples of circadian cycles of body $(-)$ and testis $(-)$ temperatures of male hedgehogs during (a) mid-winter and (b) early spring.
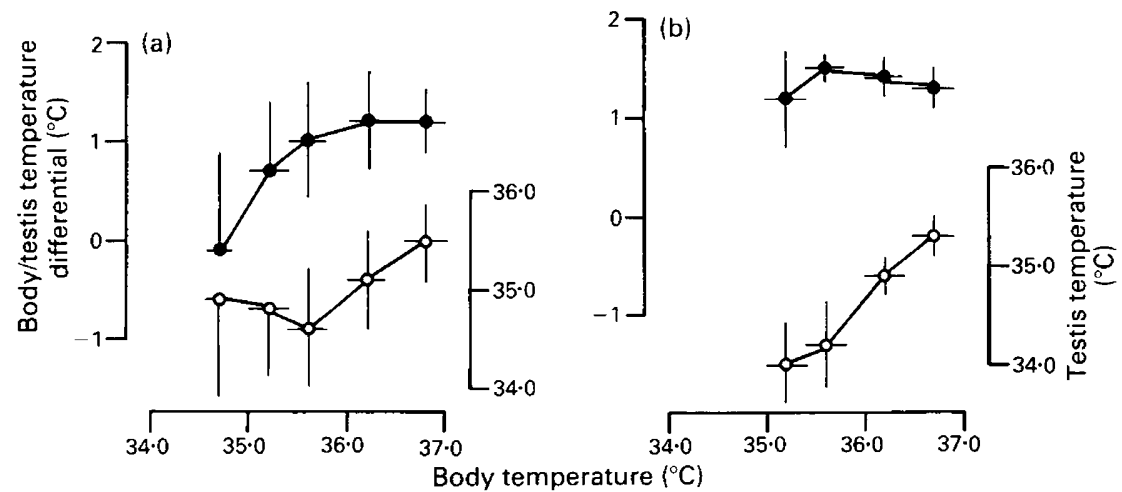

Fig. 3. Changes in the body/testis temperature differential $(O)$ and testis temperature $(O)$ with increasing body temperature in male hedgehogs (a) during hibernation and spring and (b) during spring sexual reactivation. Values are mean \pm s.d.

temperatures increasingly rose before, and fell after, testicular temperature, during arousal from and return to torpor respectively (Fig. 2). Despite this the relationship between testicular and body temperatures remained more variable during periods of heterothermy than in euthermic males.

When body temperature measurements of euthermic males only were grouped in $0.5^{\circ} \mathrm{C}$ intervals, and the corresponding body/testis temperature differentials calculated, it became evident that testicular temperature did not rise proportionally with body temperature (Fig. 3a). Because this plot used data throughout winter, the calculations were repeated (Fig. 3b) using data from midFebruary onwards when plasma testosterone concentration approaches maximal values and the testis is within 2 months of peak weight (Fowler, 1986). Only at body temperatures above $36 \cdot 2^{\circ} \mathrm{C}$ 
did testicular temperatures begin to deviate above the range $34 \cdot 0-34 \cdot 9^{\circ} \mathrm{C}$. Throughout winter, testicular temperature was between 34.0 and $35.5^{\circ} \mathrm{C}$, while body temperature for the same males varied between 34.7 and $36 \cdot 8^{\circ} \mathrm{C}$.

Testicular temperature did not correlate significantly with the body/testis temperature differential $(r=0.043, P>0.05)$, but did correlate significantly with body temperature $(r=0.992$, $P<0.001)$, which in turn correlated significantly with the body/testis temperature differential $(r=$ $0.558, P<0.01$ ). This emphasizes the lower variability of testicular compared to body temperatures, the body/testis temperature differential being a consequence of body temperature more than testicular temperature, with the latter regulated within a narrower thermal range than the former.

\section{Discussion}

In scrotal species, elevated testicular temperature affects spermatogenesis (Thwaites et al., 1982), sperm motility (Wetteman et al., 1976; Cameron \& Blackshaw, 1980), testicular androgen biosynthesis (Wetteman \& Desjardins, 1979), testicular DNA synthesis (Nishimune \& Haneji, 1981) and Sertoli Cell function (Hagenas et al., 1978). Experimental cryptorchidism may cause a complete loss of fertility of spermatozoa (Igboeli \& Foote, 1969; Glover et al., 1974) and damages primarily spermatocytes in rabbits (Ploen \& Hakansson, 1978), rats (Kerr et al., 1979) and even in heterotherms such as the opossum, Didelphis virginiana (Scott et al., 1979). Both testicular temperature and plasma/testicular androgens are important factors in epididymal sperm storage (Foldesy \& Bedford, 1982), illustrating the interdependence of temperature-susceptible processes within the testis.

Although not previously reported, the loss of a positive body/testis temperature differential during hibernal torpor is expected. However, the progressive increase in the differential between body and testicular temperatures in euthermic hedgehogs which was found in the present study, during the second half of hibernation, is unique and coincides with the recommencement of spermatogenic meiosis (Saure, 1969).

The recording of a spring body/testis temperature differential of $+1.4 \pm 0.2^{\circ} \mathrm{C}$ in the hedgehog was twice that quoted by Carrick \& Setchell (1977) for the same species, and $0.4^{\circ} \mathrm{C}$ higher than that reported by Lohiya \& Dixit (1975) for the long-eared hedgehog (Hemiechinus auritus). Both Carrick \& Setchell (1977) and Lohiya \& Dixit (1975) quoted low hedgehog body temperatures, and it may be that estimates of body/testis temperature differentials may often be depressed at lower body temperatures, as was found in the present study. Morphological observations indicated that the pampiniform plexus is present in the European hedgehog, although it remains to be confirmed histologically. Furthermore, the results obtained demonstrate that a testicular cooling mechanism is active during spermatogenesis in the hedgehog.

Most testicular reactivation probably occurs during periods of spontaneous arousal because of the depressive effects of low temperatures on cellular replication (Cameron \& Cleffmann, 1964) and metabolism. Indeed, in Syrian hamsters (Mesocricetus auratus), the degree to which the seminal vesicles of castrates respond to testosterone administration is inversely related to the time spent in deep hibernation (Lyman \& Dempsey, 1951). Hibernating hedgehogs also demonstrate coldinduced inhibition of steroidogenesis (Teravainen \& Saure, 1976). Furthermore, the direct effects of inanition, an integral part of hibernation, on spermatogenesis cannot be ruled out, as in some species, such as deer mice (Blank \& Desjardins, 1984), restriction of food intake inhibits spermatogenesis. This does not mean that there is total reproductive inactivity during torpor. Since plasma prolactin concentrations are higher during hibernation than during summer (Fowler, 1986), continued hypothalamo-pituitary-gonad axis activity is indicated. Although it is not known what proportion of the steroidogenesis which occurs during the second half of hibernation takes place when the hedgehogs are torpid, it is likely that the process is not completely arrested in torpid males. 
The fact that the body/testis temperature differential stabilized in late February, when plasma testosterone concentrations reach maximal values suggests that the full resumption of activity by Leydig cells only slightly precedes the attainment of a high body/testis temperature differential. Therefore further research would be required to elucidate whether or not rapidly rising testosterone concentrations in spring are a result of, or are responsible for, the development of a positive body/ testis temperature differential.

In terms of the changes in the body/testis temperature differential, it became clear that testicular temperatures did not increase proportionally with rising body temperatures, indicating differential regulation of body and testis temperatures. These observations support the hypothesis that in the hedgehog, as in many scrotal species, the maintenance of a lower testicular temperature is vital for spermatogenesis and sperm storage. Furthermore, up to euthermic body temperatures of $36 \cdot 2^{\circ} \mathrm{C}$ testicular temperature was maintained between 34.0 and $34.9^{\circ} \mathrm{C}$, which the present study suggests to be the optimum temperature range for the production and maturation of spermatozoa in the European hedgehog. It is clear that the body/testis temperature differential alters in relation to body temperature, with testicular temperature remaining relatively constant. Therefore the elevation of testicular temperature of the European hedgehog much above $35^{\circ} \mathrm{C}$ would probably adversely affect testicular exocrine function.

Bedford (1977) argued that the low temperature requirement of epididymal spermatozoa was the most important selection pressure in the evolution of the scrotum. This is supported by the known disruption of sperm integrity in the epididymides of some species by exposure to abdominal temperatures (Glover, 1962; Wong et al., 1982). The ascrotal caviomorph rodent Octodon degus has a body/testis temperature differential of $+0 \cdot 9^{\circ} \mathrm{C}$, but a body/epididymis temperature differential of $+4.8^{\circ} \mathrm{C}$ (Contreras \& Rosenmann, 1982). Although the epididymides of this species are located in a cremaster sac more thermoconductive than the peritoneum, the testes are insulated from the abdominal cavity by poorly vascularized epididymal fat pads. The functional significance of abdominal fat and the pampiniform plexus, in thermoregulatory terms, in the hedgehog is not known.

The regulation of testicular temperature at $34 \cdot 0-34 \cdot 9^{\circ} \mathrm{C}$ in the hedgehog is well within the normal ranges for scrotal eutherians reviewed by Waites $(1970)$, including rams $\left(34 \cdot 2-35 \cdot 3^{\circ} \mathrm{C}\right)$, bulls $\left(34 \cdot 6^{\circ} \mathrm{C}\right)$, rabbits $\left(33 \cdot 2-37 \cdot 9^{\circ} \mathrm{C}\right)$ and dogs $\left(34 \cdot 5-35 \cdot 0^{\circ} \mathrm{C}\right)$. This is further evidence that this testicular temperature range is important for sperm production, storage and maturation in the European hedgehog.

This work was supported by a postgraduate studentship from the Science and Engineering Research Council. We thank Dr M. King and Dr B. F. Robertson for assistance with the development of the automatic telemetry systems.

\section{References}

Allanson, M. (1934) Seasonal variations in the reproductive organs of the male hedgehog. Trans. Roy. Soc Lond. 223, 277-303.

Bedford, J.M. (1977) Evolution of the scrotum: the epididymis as the prime mover. In Reproduction and Evolution, pp. 171-182. Eds J. H. Calaby \& C. H. Tyndale-Biscoe. Australian Academy of Sciences, Canberra.

Blank, J.L. \& Desjardins, C. (1984) Spermatogenesis is modified by food intake in mice. Biol. Reprod. 30, 410415 .

Cameron, I.L. \& Cleffmann, G. (1964) Initiation of mitosis in relation to the cell cycle following feeding of starved chickens. J. Cell Biol. 21, 169-174.
Cameron, R.D.A. \& Blackshaw, A.W. (1980) The effect of elevated ambient temperature on spermatogenesis in the boar. J. Reprod. Fert. 59, 173-179.

Carrick, F.N. \& Setchell, B.P. (1977) The evolution of the scrotum. In Reproduction and Evolution, pp. 165-170. Eds J. H. Calaby \& C. H. Tyndale-Biscoe. Australian Academy of Sciences, Canberra.

Contreras, L.C. \& Rosenmann, M. (1982) Thermoregulation in the testes of Octodon degus: a nonscrotal rodent. J. physiol. Zool. 55, 144-147.

Dutourne, B. \& Saboureau, M. (1983) An endocrine and histophysiological study of the testicular annual cycle in the hedgehog (Erinaceus europaeus L.). Gen. comp. Endocrinol. 50, 324-332. 
Ehrenberg, L., von Ehrenstein, G. \& Hedgram, A. (1957) Gonad temperature and spontaneous mutation-rate in man. Nature, Lond. 180, 1433-1434.

Foldesy, R.G. \& Bedford, J.M. (1982) Biology of the scrotum. 1: Temperature and androgens as determinants of the sperm storage capacity of the rat cauda epididymis. Biol. Reprod. 26, 673-682.

Fowler, P.A. (1986) Aspects of heterothermy and reproduction in seasonally breeding mammals. Ph.D. thesis, University of Aberdeen.

Glover, T.D. (1962) The response of rabbit spermatozoa to artificial cryptorchidism and ligation of the epididymis. J. Endocr. 23, 317-328.

Glover, T.D., Suzuki, F. \& Racey, P.A. (1974) The role of the epididymal cells in sperm survival. In The Functional Anatomy of the Spermatozoon, pp. 359-371. Ed. B. A. Calaby. Pergamon Press, Oxford.

Hagenas, L., Ritzen, E.M., Svensson, J., Hansson, V. \& Purvis, K. (1978) Temperature dependence of Sertoli Cell function. Int. J. Androl., Suppl. 2, 449457.

Hanks, J. (1977) Comparative aspects of reproduction in the male hyrax and elephant. In Reproduction and Evolution, pp. 155-164. Eds J. H. Calaby \& C. H. Tyndale-Biscoe. Australian Academy of Sciences, Canberra.

Harrison, R.G. \& Weiner, J.S. (1949) Vascular patterns of the mammalian testis and their functional signifcance. J. exp. Biol. 26, 304-316.

Hasler, M.J. \& Nalbandov, A.V. (1974) Body and peritesticular temperatures of musk shrews (Suncus murinus). J. Reprod. Fert. 36, 397-399.

Igboeli, G. \& Foote, R.H. (1969) Changes in epididymal spermatozoa and in the testes of rabbits after experimental cryptorchidism. J. exp. Zool. 170, 489-498.

Kerr, J.B., Rich, K.A. \& de Kretser, D.M. (1979) Alterations of the fine structure and androgen secretion of the interstitial cells in the experimental cryptorchid rat testis. Biol. Reprod. 20, 409-422.

Lohiya, N.K \& Dixit, V.P. (1975) Sustained fertility in a non-scrotal mammal, the Indian hedgehog (Hemiechinus auritus collaris), after $\mathrm{CdCl}_{2}$ administration. Acta anat. 93, 296-303.

Lyman, C.P. \& Dempsey, E.W. (1951) The effect of testosterone on the seminal vesicles of castrated, hibernating, hamsters. Endocrinology 49, 647-65l.

Millar, R.P. \& Glover, T.D. (1973) Regulation of seasonal sexual activity in an ascrotal mammal, the rock hyrax, Procavia capensis. J. Reprod. Fert., Suppl. 19, 203-220.

Moore, C.R. (1923) On the relationship of the germinal epithelium to the position of the testis. Anat. Rec. 25, 142-143.

Moore, C.R. (1926) The biology of the mammalian testis and scrotum. Quart. Rev. Biol. 1, 4-50.
Nishimune, Y. \& Haneji, T. (1981) Testicular DNA synthesis in vivo: comparison between unilaterally cryptorchid testis and contralateral intact testis in the mouse. Archs Androl. 6, 61-65.

Phillips, R.W. \& McKenzie, F.F. (1934) The thermoregulatory function and mechanisms of the scrotum. Missouri Univ. Agric. Exp. Stn, Res. Bull. 217, 1-73.

Ploen, L. \& Hakansson, N. (1978) Abnormal epididymal spermatozoa two to thirty-five days after brief cryptorchidism in the rabbit. Int. J. Androl. 1, 250-261.

Saboureau, M. (1981) Envirenmental factors and regulation of the annual testicular cycle in a breeding hibernating mammal: the hedgehog. In Photoperiodism and Reproduction in Vertebrates, pp. 319-337. INRA, Nouzilly.

Saure, L. (1969) Histological studies on the sexual cycle of the male hedgehog (Erinaceus europaeus L.). Aquilo Ser. Zool. 9, I-43.

Scott, J.N., Fritz, H.I. \& Nagy, F. (1979) Response to cryptorchidism of the testis and epididymis of the opossum (Didelphis virginiana). J. Reprod. Fert. 57, 175-178.

Setchell, B.P. (1978) Naturally occurring and induced dysfunctions of the testis. In The Mammalian Testis, pp. 359 423. Paul Elek, London.

Snedecor, G.W. \& Cochran, W.G. (1980) Statistical Methods, 7th edn, pp. 149-174. Iowa State University Press, Ames.

Teravainen, T. \& Saure, A. (1976) Changes in the testicular metabolism of dehydroepiandrosterone during the annual cycle of the hedgehog (Erinaceus europaeus L.). Gen comp. Endocrinol. 29, 328-332.

Thwaites, C.J., Stapleton, D.L., Hinch, G.N. \& Edey, T.N. (1982) Testicular temperature and sperm production in induced cryptorchid lambs. Aust. vet. J. 58, 123, Abstr.

Waites, G.M.H. (1970) Temperature regulation and the testis. In The Testis, Vol. 1, pp. 241-279. Eds A. D. Johnson, W. R. Gomes \& N. L. VanDenmark. Academic Press, New York.

Waites, G.M.H. (1976) Temperature regulation and fertility in male and female mammals. Israel J. med. Sci. 9, 982-993.

Wettemann, R.P. \& Desjardins, C. (1979) Testicular function in boars exposed to elevated ambient temperature. Biol. Reprod. 20, 235-241.

Wislocki, G.B. (1933) Location of the testes and body temperature in mammals. Quart. Rev. Biol. 8, 385-396.

Wong, P.Y.D., Au, C.L. \& Bedford, J.M. (1982) Biology of the scrotum. II. Suppression by abdominal temperatures of transepithelial ion and water transport in the cauda epididymis. Biol. Reprod. 26, 683-689.

Zar, J.H. (1984) Biostatistical Analysis, 2 edn, pp. 162-184. Prentice-Hall Inc., Englewood Cliffs. 